\title{
Perancangan Jaringan Wifi Dengan Menggunakan Mikrotik Pada SMP Negeri 3 Mallusetasi Kabupaten Barru
}

\author{
Musdalifa $^{1}$, Surahmin Adna Panu ${ }^{2}$ \\ ${ }^{1}$ Sekolah Tinggi Ilmu Administrasi (STIA) Al Gazali Barru, Sulawesi Selatan \\ ${ }^{2}$ SMPN 3 Mallusetasi Kabupaten Barru, Sulawesi Selatan \\ ${ }^{1}$ musdalifah@algazali.ac.id \\ 2amigortal@gmail.com
}

\begin{abstract}
ABSTRAK
Penelitian ini bertujuan untuk melakukan (1) Perancangan Topologi jaringan WIFI dengan Menggunakan Router Mikrotik Pada SMPN 3 Mallusetasi kabupaten Barru, (2) Instalasi dan konfigurasi Router Mikrotik ke jaringan Pada SMPN 3 Mallusetasi kabupaten Barru. Metode penelitian yang digunakan meliputi; studi pustaka, wawancara, dan studi lapangan. Studi pustaka dilakukan untuk mengumpulkan basis pengetahuan dalam perancangan. Studi lapangan dilakukan untuk mengumpulkan data dan informasi mengenai kondisi yang ada dan juga evaluasi atas perancangan yang dihasilkan. Hasil yang dicapai adalah rancangan lokasi accsess point dan area jangkauan accsess point. Kesimpulan yang didapat adalah dengan melakukan pembangunan sistem jaringan nirkabel untuk proses belajar mengajar di SMPN 3 Mallusetasi Kabupaten Barru, sehingga pembelajaran computer dan internet di sekolah menjadi lebih optimal.
\end{abstract}

Kata Kunci: Jaringan WIFI, Mikrotik

\section{PENDAHULUAN}

Sesuai perkembangan ilmu pengetahuan dan teknologi saat ini, serta modernisasi zaman yang begitu pesat, maka telah memacu kita agar dapat mengikuti perkembangan tersebut tanpa terkecuali. Salah satu perkembangan yang sangat spektakuler pada dasawarsa terakhir adalah perkembangan teknologi jaringan komunikasi dan informasi, baik melalui telephone seluler maupun melalui internet. Oleh karena itu, sekolah sebagai salah satu wadah pendidikan generasi bangsa dituntut untuk terus mengikuti arah perkembangan itu dengan melengkapi berbagai sarana dan prasarana telekomunikasi, khususnya internet sebagai wadah bagi guru dan siswa untuk mengakses berbagai informasi pengetahuan.

Teknologi jaringan saat ini berkembang sangat pesat, mulai dari jaringan yang menggunakan kabel sampai pada jaringan tanpa kabel dalam hal ini WIFI (Warless Frekuensi LAN). Teknologi WLAN (menggunakan standar radio yang sekarang umum disebut dengan WiFi) telah menjadi teknologi inventori yang handal. Manajer TI di perusahaan-perusahaan ritel besar pun diminta untuk membangun infrastruktur nirkabel guna mendukung berbagai perangkat nirkabel dan aplikasi bergerak (mobile) yang baru, yang diterapkan untuk skala perusahaan. Hal ini menjadi pemicu bagi dunia pendidikan atau sekolah-sekolah untuk mengembangkan pusat informasi pengetahuan melalui teknologi WIFI. Pada prinsipnya bahwa jaringan komputer adalah sekelompok komputer yang saling berhubungan satu sama lain dengan memanfaatkan media komunikasi dan suatu protokol komunikasi, sehingga antar komputer dapat saling berbagi dan bertukar informasi. Manfaat dari jaringan komputer sudah merupakan sesuatu kebutuhan bagi siswa dalam memecahkan masalah-masalah pembelajaran. Jaringan komputer sering kali berperan vital dalam kegiatan pendistribusian informasi yang cepat tersebut. Semua dari komponen yang tergabung dalam jaringan komputer tersebut haruslah mampu saling mendukung untuk menghasilkan satu sistem yang kokoh dan handal untuk melayani setiap permintaan informasi yang dibutuhkan oleh pengguna.

SMP Negeri 3 Mallusetasi sangat memerlukan teknologi jaringan internet yang lebih mobile karena jarak antar gedung cukup berjauhan, apalagi jarak laboratorium computer dengan gedung kantor berjarak cukup jauh. Untuk lebih efisien dan efektif dalam pemanfaatan jaringan computer dan internet, maka perancangan teknologi WIFI pada SMP 
Negeri 3 Mallusetasi menjadi sesuatu yang sangat penting.

Permasalahan penting yang perlu di atasi adalah bagaimana merancang sebuah jaringan Wifi dengan menggunakan Router Mikrotik untuk mengoptimalkan proses pembelajaran internet di laboratorium SMP Negeri 3 Mallusetasi Kabupaten Barru. Oleh karena itu, beberapa masalah yang perlu dijawab dalam penelitian ini adalah; (1) bagaimana Perancangan Topologi jaringan WIFI dengan Menggunakan Router Mikrotik Pada SMPN 3 Mallusetasi kabupaten Barru; (2) bagaimana melakukan Instalasi dan konfigurasi Router Mikrotik ke jaringan Pada SMPN 3 Mallusetasi Kabupaten Barru.

Tujuan yang hendak dicapai dalam penelitian ini secara umum adalah mengoptimalkan proses belajar internet di laboratorium komputer sekaligus memudahkan akses internet bagi guru dan siswa untuk dalam proses pembelajaran pada mata pelajaran lainnya di SMP Negeri 3 Mallusetas. Secara lebih khusus penelitian ini bertujuan untuk membuat rancangan topologi jaringan WIFI dengan menggunakan router mikrotik sekaligus melakukan instalasi dan konfigurasi Router mikrotik pada sistem jaringan yang dibangun.

Dampak dan manfaat penelitian diharapkan dapat menambah fasilitas laboratorium yang memudahkan siswa untuk belajar internet dan menggunakan internet dalam menyelesaikan tugas pembelajaran. mempermudah dan mempercepat seorang guru untuk mengambil hasil pekerjaan siswa/siswinya; mempermudah dan mempercepat seorang guru untuk memberikan penilaian terhadap hasil pekerjaan siswa; dan secara teknis penelitian ini mampu mengefektifkan penggunaan harddisk pada sisi komputer klien, sehingga harddisk pada komputer klien tidak cepat penuh;

Sebuah jaringan terdiri dari 2 atau lebih komputer yang saling berhubungan diantara satu dengan yang lain, dan saling berbagi sumber daya Konsep jaringan komputer lahir pada tahun 1940-an di Amerika dari sebuah proyek pengembangan komputer MODEL I di laboratorium Bell dan group riset Harvard University yang dipimpin profesor $\mathrm{H}$. Aiken.

Pada mulanya proyek tersebut hanyalah ingin memanfaatkan sebuah perangkat komputer yang harus dipakai bersama. Untuk mengerjakan beberapa proses tanpa banyak membuang waktu kosong dibuatlah proses beruntun (Batch Processing), sehingga beberapa program bisa dijalankan dalam sebuah komputer dengan kaidah antrian.

Jaringan komputer adalah sekelompok komputer otonom yang saling berhubungan antara satu dengan lainnya menggunakan protokol komunikasi melalui media komunikasi sehingga dapat saling berbagi informasi, program-program, penggunaan bersama perangkat keras seperti printer, harddisk, dan sebagainya. Selain itu jaringan komputer bisa diartikan sebagai kumpulan sejumlah terminal komunikasi yang berada diberbagai lokasi yang terdiri dari lebih satu komputer yang saling berhubungan.

Topologi jaringan adalah perihal yang menjelaskan hubungan geometris antara unsurunsur dasar penyusun jaringan, yaitu node, link, dan station. (Wikipedia, 2009). Topologi Jaringan dibagi menjadi dua, yaitu topologi fisik dan topologi logis. Topologi fisik menjelaskan susunan jaringan komputer secara fisik. Topologi fisik menguraikan bagaimana komputer, media jaringan, dan letak-letak dari komponen jaringan komputer ditempatkan. Ghazali (2008) mengatakan bahwa bagaimana komponen jaringan komputer disusun dan diletakkan pada tempat tertentu. sedangkan topologi logis menetapkan bagaimana informasi atau aliran data dalam jaringan. Menurut Dwiantoro (2005) Topologi logis menguraikan bagaimana data mengalir sepanjang komponen fisik.

Jenis-Jenis Jaringan Berdasarkan Ruang Lingkupnya dapat dibagi menjadi 4 (empat) jenis, yaitu;

\section{Local Area Network (LAN)}

Sebuah LAN adalah jaringan yang dibatasi oleh area yang relatif kecil, umumnya dibatasi oleh area lingkungan seperti; sebuah perkantoran di sebuah gedung, atau sebuah sekolah, dan biasanya tidak jauh dari sekitar 1 $\mathrm{km}$ persegi. Komputer-komputer yang terhubung ke dalam jaringan (network) itu biasanya disebut dengan workstation. Biasanya kemampuan workstation lebih di bawah dari file server dan mempunyai aplikasi lain di dalam harddisknya selain aplikasi untuk jaringan. Kebanyakan LAN menggunakan media kabel untuk menghubungkan antara satu komputer dengan komputer lainnya. Ukuran LAN terbatas, sehingga dapat menggunakan desain tertentu. Teknologi transmisi kabel tunggal memiliki kecepatan 10 hingga 100 Mbps. 


\section{Metropolitan Area Network (MAN)}

Sebuah MAN, biasanya meliputi area yang lebih besar dari LAN, misalnya antar wilayah dalam satu propinsi. Dalam hal ini jaringan menghubungkan beberapa buah jaringan-jaringan kecil ke dalam lingkungan area yang lebih.

\section{Wide Area Network (WAN)}

Jaringan area Skala Besar Wide Area Networks (WAN) adalah jaringan yang lingkupnya biasanya sudah menggunakan sarana Satelit ataupun kabel bawah laut sebagai contoh keseluruhan jaringan BANK BNI yang ada di Indonesia ataupun yang ada di Negara-negara lain. Menggunakan sarana WAN, Sebuah Bank yang ada di Bandung bisa menghubungi kantor cabangnya yang ada di Hongkong, hanya dalam beberapa menit.

4. Jaringan tanpa kabel (wireless)

Dari tipe jaringan komputer tersebut di atas akan dibahas jaringan LAN dan Jaringan tanpa kabel (wireless).

1) Jaringan LAN (Local Area Network)

Jaringan LAN adalah jaringan yang menghubungkan beberapa komputer dalam satu lokal area (biasanya dalam satu gedung atau antar gedung). Biasanya digunakan dalam rumah, perkantoran, perindustrian, universitas atau akademik, rumah sakit, dan daerah yang sejenis. Pada jaringan LAN kecepatan transmisi data dapat mencapai 1 sampai 100 megabit perdetik. Berbagai tipe LAN telah dibangun dan diinstalasi, namun beberapa tipe menjadi lebih dominan dari yang lain.

Sistem LAN yang sering digunakan adalah sistem ethernet yang dikembangkan oleh perusahaan Xerox. Secara garis besar, LAN adalah sebuah jaringan komunikasi yang memiliki ciri-ciri, meliputi: bersifat lokal (misal 1 gedung atau antar gedung); dikontrol oleh satu kekuasaaan administrative; pengguna dalam sebuah lan dianggap dapat dipercaya; biasanya mempunyai kecepatan yang tinggi dan data dalam semua komputer selalu dishering.

Beberapa keuntungan menggunakan LAN adalah: (1) akses data antar komputer berlangsung cepat dan mudah; (2) dapat menghubungkan banyak computer; (3) dapat terkoneksi ke internet; (4) back up data berlangsung lebih cepat dan mudah.

\section{2) Jaringan Tanpa Kabel (WIRELESS)}

Teknologi wireless adalah salah satu pilihan yang tepat untuk menggantikan teknologi jaringan yang terdiri dari banyak kabel dan sebuah solusi akibat jarak antar jaringan yang tidak dihubungkan melalui kabel. Banyak keuntungan sistem jaringan WiFi (Wireless Fidelity), yaitu pengguna tidak dibatasi ruang geraknya, tetapi dibatasi oleh jarak jangkauan pemancar WiFi. Pemancar WiFi mampu menjangkau area 100 feet atau 30 $\mathrm{m}^{2}$. Apabila menginginkan jangkauan lebih jauh lagi, dapat diperkuat menggunakan perangkat khusus seperti booster yang berfungsi sebagai relay dan mampu menjangkau ratusan meter bahkan beberapa kilometer.

Jaringan tanpa kabel memiliki dua cara menghubungkan antar-PC dengan sistem wireless, yaitu; (1) sistem ad hoc dan (2) sistem Infra Structure yang menggunakan Access Point. Sistem ad hoc merupakan hubungan antar-PC berdasarkan nama SSID (Servise Set IDentifier). SSID adalah nama komputer yang memiliki card, USB, dan perangkat wireless. Setiap perangkat harus diberi nama sesuai identitas. Sistem ad hoc adalah sistem peer to peer. Maksudnya, sebuah komputer akan dihubungkan dengan sebuah komputer lainnya agar saling mengenal SSID.

Sistem Infra Structure membutuhkan sebuah perangkat khusus yang dapat difungsikan sebagai akses poin. Koneksi Infra Structure menggunakan access point membutuhkan paling tidak sebuah jaringan wireless network yang memiliki satu tititk di satu tempat, sehingga komputer lain dapat mencari dan menerima sinyal agar bisa masuk ke dalam jaringan network tersebut.

Komponen logic dari access point adalah ESSID (Extended Service Set IDentification) yang merupakan standar dari IEEE 802.11. pengguna harus mengkoneksikan wireless adapter ke Access Point dengan ESSID tertentu supaya transfer data bisa terjadi. ESSID menjadi autentifikasi standar dalam komunikasi wireless. Dalam segi keamanan beberapa vendor tertentu membuat kunci autentifikasi tertentu untuk proses autentifikasi dari klien.

\section{Protokol dalam Jaringan}

Sebagian besar jaringan disusun sebagai tumpukan layer. atau level, hal ini dilakukan untuk mengurangi kerumitan perancangan perangkat lunak jaringan. Jumlah, nama, isi, dan fungsi dari setiap layer berbeda untuk jaringan yang berbeda, tetapi semua layer pada jaringan dibuat dengan tujuan melayani layer yang berada di atasnya. 
Layanan dan protokol merupakan dua hal yang berbeda. Layanan merupakan sekumpulan primitive/operasi yang disediakan sebuah layer untuk layer di atasnya. Sedangkan protocol adalah sejumlah aturan yang mengatur format dan arti sebuah frame, paket atau pesan yang dilewatkan antara dua peer entity dalam sebuah layer.

Protokol adalah aturan-aturan main yang mengatur komunikasi diantara beberapa komputer di dalam sebuah jaringan, aturan itu termasuk di dalamnya petunjuk yang berlaku bagi cara-cara atau metode mengakses sebuah jaringan, topologi fisik, tipe-tipe kabel dan kecepatan transfer data. Protokol-Protokol yang dikenal adalah sebagai berikut:

1. Ethernet, adalah sistem jaringan yang dibuat dan dipatenkan perusahaan Xerox. Kecepatan Ethernet waktu itu hanya $3 \mathrm{Mbps}$ dan dikenali sebagai Experimental Ethernet. Ethernet adalah implementasi metoda CSMA/CD (Carrier Sense Multiple Access with Collision Detection) Standarisasi sistem ethernet dilakukan sejak tahun 1978 oleh IEEE. Kecepatan transmisi data di ethernet sampai saat ini adalah 10 sampai 100 Mbps. Saat ini yang umum ada dipasaran adalah ethernet berkecepatan 10 Mbps - 100 Mbps yang biasa disebut seri 10Base/100Base. Ada bermacam-macam jenis 10Base diantaranya adalah: 10Base5, 10Base2, 10BaseT, dan 10BaseF

2. Token Ring, berbasis standar IEEE 802.5 dan beroperasi pada 4 atau 16 MBps. Dengan Token-Ring, devais network secara fisik terhubung dalam konfigurasi ring dimana data dilewatkan dari devais ke devais secara berurutan. Sebuah paket kontrol, yang dikenal sebagai kontrol token, juga dilewatkan dalam ring. Devais yang ingin mentransmit data akan mengambil token, mengisinya dengan data dan dikembalikan ke ring. Devais penerima akan mengambil token tersebut, lalu mengosongkan isinya dan dikembalikan ke ring. Protokol ini mencegah terjadinya kolisi data dan menghasilkan performansi yang lebih baik pada penggunaan high-level bandwidth. Ada tiga tipe pengembangan dari Token Ring dasar: full duplex, switched dan 100VGAnyLAN. Token Ring Full Duplex menggandakan bandwidth yang tersedia bagi devais pada network. Switched Token Ring menggunakan switch yang mentransmisikan data antara segmen LAN, tidak antara devais LAN tunggal. Standar 100VG-AnyLAN mendukung format
Ethernet dan Token Ring pada kecepatan $100 \mathrm{MBps}$

3. FDDI, adalah pasangan teknologi LAN Ethernet IEEE 802 yang mendukung data transfer 100 MBps untuk jarak sampai 100 $\mathrm{km}$. FDDI bukan standar IEEE dan beroperasi di atas kabel fiber optik dengan menggunakan arsitektur ring counter-ruting kembar yang dapat menghubungkan sampai 500 devais per ring. Ring kembar memungkinkan LAN tetap beroperasi bila terjadi kegagalan pada salah satu ring atau node.

4. ATM, beroperasi mulai dari 25 MBps sampai 622 MBps. ATM adalah suatu bentuk teknologi paket switching yang menggunakan sel data dengan panjang tetap (53 byte) pada sirkuit virtual. Dengan ukuran sel data yang tetap dan kecil, memungkinkan switching pada kecepatan dengan throughput tinggi. Dengan delay yang sangat kecil dan waktu interval yang tetap antar sel data, memungkinkan aplikasi suara dan video dikirim lewat LAN dan berbagai jenis tipe data yang berbeda digabungkan dalam network yang sama.

\section{Protokol TCP/IP}

TCP/IP (Transmission Control Protocol/Internet Protocol) adalah standar komunikasi data yang digunakan oleh komunitas internet dalam proses tukarmenukar data dari satu komputer ke komputer lain di dalam jaringan Internet. Protokol ini tidaklah dapat berdiri sendiri, karena memang protokol ini berupa kumpulan protokol (protocol suite). Protokol ini juga merupakan protokol yang paling banyak digunakan saat ini.

\section{Router Mikrotik}

Router mikrotik hampir sama dengan Bridge Router akan mencari jalur yang terbaik untuk mengirimkan sebuah pesan yang berdasakan atas alamat tujuan dan alamat asal. Sementara Bridges dapat mengetahui alamat masing-masing komputer dimasing-masing sisi jaringan, router mengetahui alamat komputer, bridges dan router lainnya. Router dapat mengetahui keseluruhan jaringan melihat sisi mana yang paling sibuk dan dia bisa menarik data dari sisi yang sibuk tersebut sampai sisi tersebut bersih. Sebuah Router mengartikan informasi dari satu jaringan ke jaringan yang lain.

Jika sebuah jaringan LAN menginginkan terkoneksi ke Internet, maka 
dibutuhkan sebuah router, biasanya berupa PC Router maupun Perangkat Router Wireless. Ini berarti sebuah router dapat menerjemahkan informasi diantara LAN anda dan Internet. ini juga berarti mencarikan alternatif jalur yang terbaik untuk mengirimkan data melewati internet. Ini berarti bahwa Router itu dapat berfungsi, yaitu: (1) mengatur jalur sinyal secara efisien; (2) mengatur pesan diantara dua buah protocol; (3) mengatur pesan diantara topologi jaringan linear bus dan bintang(star); (4) mengatur pesan diantara melewati kabel fiber optic, kabel koaksial atau kabel twisted pair.

Beberapa produk yang bisa digunakan sebagai router, yaitu; (1) Access Point (AP), yaitu bridge yang biasanya dipasang pada Base Station; (2) Remote Outdoor Router (ROR), yaitu router yang biasanya dipasang pada Client Station; (3) Central Outdoor Router (COR), dapat sebagai bridge atau router dan biasanya dirancang khusus untuk Base Station; Angin Office Router; Angin Base Router

\section{Pengenalan Router Mikrotik}

Mikrotik didesain untuk mudah digunakan dan sangat baik digunakan untuk keperluan administrasi jaringan komputer seperti merancang dan membangun sebuah sistem jaringan komputer skala kecil hingga yang kompleks sekalipun. Mikrotik dibuat oleh MikroTikls sebuah perusahaan di kota Riga, Latvia. Bagi yang belum tau, Latvia adalah sebuah negara yang merupakan "pecahan" dari negara Uni Soviet dulunya atau Rusia sekarang ini.

Dengan nama merek dagang Mikrotik mulai didirikan tahun 1995 yang pada awalnya ditujukan untuk perusahaan jasa layanan Internet (PJI) atau Internet Service Provider (ISP) yang melayani pelanggannya menggunakan teknologi nirkabel atau wireless. Saat ini MikroTikls memberikan layanan kepada banyak ISP nirkabel untuk layanan akses Internet dibanyak negara di dunia dan juga sangat populer di Indonesia.

Mikrotik pada standar perangkat keras berbasiskan Personal Computer (PC) dikenal dengan kestabilan, kualitas kontrol dan fleksibilitas untuk berbagai jenis paket data dan penanganan proses rute atau lebih dikenal dengan istilah routing. Mikrotik yang dibuat sebagai router berbasiskan PC banyak bermanfaat untuk sebuah ISP yang ingin menjalankan beberapa aplikasi mulai dari hal yang paling ringan hingga tingkat lanjut. Contoh aplikasi yang dapat diterapkan dengan adanya Mikrotik selain routing adalah aplikasi kapasitas akses (bandwidth) manajemen, firewall, wireless access point (WiFi), backhaul link, sistem hotspot, Virtual Private Netword (VPN) server dan masih banyak lainnya.

Mikrotik bukanlah perangkat lunak yang gratis jika kamu ingin memanfaatkannya secara penuh, dibutuhkan lisensi dari MikroTikls untuk dapat menggunakanya alias berbayar. Mikrotik dikenal dengan istilah Level pada lisensinya. Tersedia mulai dari Level 0 kemudian 1, 3 hingga 6, untuk Level 1 adalah versi Demo Mikrotik dapat digunakan secara gratis dengan fungsi-fungsi yang sangat terbatas. Tentunya setiap level memilki kemampuan yang berbeda-beda sesuai dengan harganya, Level 6 adalah level tertinggi dengan fungsi yang paling lengkap.

Secara singkat keenam level dalam Router Mikrotik dapat jelaskan sebagai berikut:

- Level 0 (gratis); tidak membutuhkan lisensi untuk menggunakannya dan penggunaan fitur hanya dibatasi selama 24 jam setelah instalasi.

- Level 1 (demo); pada level ini kamu dapat menggunakannya sbg fungsi routing standar saja dengan 1 pengaturan serta tidak memiliki limitasi waktu untuk menggunakannya.

- Level 3; sudah mencakup level 1 ditambah dengan kemampuan untuk menajemen segala perangkat keras yang berbasiskan Kartu Jaringan atau Ethernet dan pengelolan perangkat wireless tipe klien.

- Level 4; sudah mencakup level 1 dan 3 ditambah dengan kemampuan untuk mengelola perangkat wireless tipe akses poin.

- Level 5; mencakup level 1, 3 dan 4 ditambah dengan kemampuan mengelola jumlah pengguna hotspot yang lebih banyak.

- Level 6; mencakup semua level dan tidak memiliki limitasi apapun.

Apabila kita ingin sekedar untuk mencoba-coba silakan gunakan Level 1 sebagai awal. Sedangkan untuk yang ingin menggunakan seluruh fitur dari Mikrotik maka mau tidak mau harus membeli lisensinya. Setiap file Mikrotik yang telah di instalasi pada sebuah komputer akan bertahan selama 24 jam sejak pertama kali diinstal. Jika komputer dimatikan saat waktu masih kurang dari 24 jam maka masih ada sisa waktunya untuk terus dapat menggunakannya. Jika masa 24 jam 
telah lewat maka Mikrotik sudah tidak dapat digunakan lagi dan membutuhkan proses instalasi ulang.

Sistem lisensi perangkat lunak Mikrotik atau lebih dikenal dengan sebutan Router OS berbasiskan identitas dari perangkat lunak itu sendiri atau disebut Software ID. Jika ingin merubah lisensinya maka wajib mengetahui Software ID tersebut, ini dapat temukan saat proses instalasi berlangsung. Jika terlewat saat melihat Software ID atau lupa mencatat maka dapat melihatnya kembali melalui sistem konsol atau melalui perangkat lunak tambahan dari Mikrotik berbasiskan Windows yaitu Winbox. Mikrotik menerapkan sistem level lisensi yang baru. Dengan adanya sistem level lisensi yang baru ini, diharapkan pengguna lebih diuntungkan, karena harganya yang lebih murah dan jangka waktu free upgrade yang lebih lama (sekarang menjadi 3 tahun untuk level 5 dan 6). (Sumber http://mikrotik.co.id).

\section{METODE PENELITIAN}

Jenis penelitian ini adalah penelitian eksperimen dengan menggunakan metode eksperimen partisipatif dimana peneliti terlibat langsung pada obyek yang diteliti. Obyek penelitian adalah ruang kantor dan Laboratorium Komputer pada SMP Negeri 3 Mallusetasi Kabupaten Barru. Teknik dan prosedur pengumpulan data baik data primer maupun data sekunder diperoleh melalui metode kepustakaan, wawancara dan penelitian lapangan. Metode kepustakaan, yaitu; pengumpulan data dengan cara mencari buku yang terkait dengan pembahasan serta artikel-artikel tentang perancangan jaringan dengan menggunakan mikrotik. Wawancara yang berupa pedoman wawancara yang berisi indikator tentang tentang pentingnya perancangan jaringan dengan menggunakan mikrotik bagi proses pembelajaran internet dan pembelajaran lainnya di sekolah. Sedangkan penelitian lapangan, yaitu; kegiatan yang dilakukan dengan cara mengumpulkan data secara langsung dari objek penelitian melalui lembar observasi yang berisi indikator kebutuhan perancangan jaringan dengan menggunakan mikrotik.

\section{HASIL \& PEMBAHASAN}

Secara geografis, SMP Negeri 3 Mallusetasi merupakan salah satu sekolah yang ada di bukit Topporeng sekitar $2 \mathrm{~km}$ dari Ibu Kota Kecamatan Mallusetasi kearah timur.
SMPN 3 Mallusetasi didirikan pada tahun 1998. Selama 13 tahun perjalanannya, SMPN 3 Mallusetasi sampai saat ini masih tetap eksis dan memiliki sejumlah prestasi, baik bidang akademik maupun non akademik. Jumlah siswa rata-rata dalam tiga tahun terakhir sebanyak 180 orang yang terdiri dari 9 kelas, kelas VII tiga rombel, Kelas VIII tiga rombel, dan Kelas IX tiga Rombel.

Kualifikasi tenaga guru baik PNS maupun Non PNS semuanya berpendidikan S1, selain itu 3 orang diantaranya berpendidikan S2, 1 orang sementara menyelesaikan S2. Demikian pula dengan pegawai, berjumlah 4 orang yang terdiri dari 2 orang berpendidikan S1 dan 2 orang lainnya SLTA. Dari segi sarana dan prasarana gedung dipandang telah memadai.

Demikian pula, dengan fasilitas belajar mengajar dapat dikatakan cukup memadai baik dari ketersediaan buku-buku pelajaran maupun peralatan pembelajaran lainnya. Dari aspek teknologi informasi computer, sekolah ini sejak tahun 2008 telah menggunakan computer kantor. Tahun 2009 telah memiliki ruang laboratorium computer. Pembelajaran computer dasar dilaksanakan di laboratorium, sedangkan untuk pembelajaran tentang jaringan seperti internet, dilaksanakan dengan menggunakan jasa pihak ketiga dalam hal ini dibawa ke tempat warnet yang terdekat. Kondisi ini telah berlangsung selama dua tahun terakhir.

Adapun visi dan misi SMPN 3 Mallusetasi dapat dikemukakan sebagai berikut: Terkemuka dalam Mutu, Berbudi Pekerti Luhur, Beriman dan Bertaqwa. Misinya, yaitu; (1) meningkatkan mutu pembelajaran secara efektif agar siswa berkesempatan mengembangkan diri secara optimal sesuai potensi yang dimilikinya; (2) menggali potensi bakat siswa bidang olahraga, seni budaya dan agama; (3) memberdayakan masyarakat untuk peduli pendidikan; (4) melestarikan lingkungan dan mengembangkan sekolah sehat.

Selanjutnya, atas keputusan bersama bahwa Standar Kelulusan siswa SMP Negeri 3 Mallusetasi sebagai berikut: (1) mampu menampilkan kebiasaan sopan santun dan berbudi pekerti sebagai cerminan akhlak mulia; (2) mampu berbahasa Inggris secara aktif; (3) mampu mengaktualisasikan diri dalam berbagai seni dan olah raga, sesuai minat dan bakat siswa; (4) Mampu mengoperasikan komputer secara aktif untuk program microsoft word dan excel serta mengenal dan 
memahami dunia internet sebagai salah satu sumber informasi ilmu pengetahuan global; (5) mampu bersaing dalam mengikuti berbagai kompetisi akademik dan non akademik di tingkat kecamatan, kabupaten/kota, propinsi, dan nasional; (6) mampu memiliki kecakapan hidup personal, sosial, environmental dan pravocasional; (7) mampu melanjutkan ke sma/smk sesuai pilihan siswa.

Secara nyata sekolah telah mencantumkan dalam standar kelulusan bahwa siswa harus Mampu mengoperasikan komputer secara aktif untuk program microsoft word dan excel serta mengenal dan memahami dunia internet sebagai salah satu sumber informasi ilmu pengetahuan global. Hal ini berarti, pembangunan jaringan pada SMPN 3 Mallusetasi telah menjadi syarat wajib bagi kelulusan siswa. Oleh karena itu, pembangunan jaringan yang menggunakan mikrotik pada penelitian ini diharapkan dapat memudahkan proses pembelajaran umunya, khususnya pelajaran internet dalam TIK sekaligus membantu penyelenggaraan administrasi sekolah.

Gambaran tentang kondisi objektif keberadaan Komputer PC pada laboratorium komputer dan tata usaha pada SMPN 3 Mallusetasi, dan laptop pada beberapa orang guru, yaitu; Tata Usaha 2 Unit PC, Kepala Sekolah 1 Unit PC, Lab Komputer 7 Unit PC,
8 Unit Laptop pada guru. Jadi jumlah PC sebanyak 10 Unit dan 8 Unit Laptop.

Kebutuhan jaringan untuk proses mengajar guru yang menggunakan laptop bukan lagi menjadi kendala karena masingmasing memiliki modem bahkan menggunakan hp android yang terhubung langsung ke jaringan internet. Akan tetapi kebutuhan jaringan internet untuk proses belajar siswa yang menggunakan PC menjadi kendala karena belum memiliki perangkat tambahan yang bisa terhubung ke jaringan internet. Oleh karena itu, salah satu solusinya adalah perancangan jaringan internet dengan menggunakan mikrotik.

Selanjutnya, dapat digambarkan keberadaan perangkat keras, perangkat lunak, dan perangkat akal, yaitu;

1. Perangkat Keras (Hardware)

Dari segi penggunaan hardware yang ada di SMPN 3 Mallusetasi tujuh unit komputer yang semuanya sudah menggunakan komputer standar. Dimana sudah memiliki kapasitas penyimpanan data yang tinggi, begitupun dengan procecornya yang sudah menggunakan intel atom, dual core, dan core 2 duo.

Untuk lebih jelasnya mengenai spesifikasi dari perangkat keras dari komputerkomputer tersebut, dapat anda lihat melalui tabel di bawah ini :

Tabel 1. Spesifikasi Hardware Komputer 1 dan 2 Bag. TU

\begin{tabular}{lll}
\hline Type/Jenis & Merek & Kapasitas/ Spesifikasi \\
\hline Prosessor & Intel Dual Core & \\
\hline Memory & Visipro & $1 \mathrm{~GB}$ \\
\hline Harddisk & Seagate & $120 \mathrm{~GB}$ \\
\hline Floppy Disk & LG & $52 \mathrm{x}$ \\
\hline Monitor & LG & 14 inchi \\
\hline Mouse & PS2 & \\
\hline Printer & Canon IP 2700 & \\
\hline
\end{tabular}

Tabel 2. Spesifikasi Hardware Komputer 3 Ruang Kepsek

\begin{tabular}{|l|l|l|}
\hline Type/Jenis & Merek & Kapasitas \\
\hline Prosessor & Intel Pentium Core 2 Duo & $2,8 \mathrm{GHz}$ \\
\hline Memory & Visipro & $1 \mathrm{~GB}$ \\
\hline Harddisk & Seagate & $160 \mathrm{~GB}$ \\
\hline CD-Rom & LG & $52 \mathrm{x}$ \\
\hline Monitor & LG & 14 inchi \\
\hline Mouse/ Keyboard & PS2 & \\
\hline Printer & Canon IP 2700 & \\
\hline
\end{tabular}


Tabel 3. Spesifikasi Hardware 4, 5, 6, 7, 8, 9, dan 10 Lab. Komputer

\begin{tabular}{|c|c|c|}
\hline Type/Jenis & Merek & Kapasitas \\
\hline Prosessor & Intel atom & $1,72 \mathrm{GHz}$ \\
\hline Memory & Visipro & $1 \mathrm{~GB}$ \\
\hline Harddisk & Seagate & $160 \mathrm{~GB}$ \\
\hline CD-Rom & LG & $52 \mathrm{x}$ \\
\hline Monitor & LG & 14 inchi \\
\hline Mouse/ Keyboard & PS2 & \\
\hline
\end{tabular}

\section{Perangkat Lunak (Software)}

Untuk penggunaan perangkat lunak (software) sebagian besar komputer yang ada pada SMPN Mallusetasi sudah menggunakan sistem operasi Window SP.2 sebagai sistem operasi dalam menunjang sistem operasional sekolah. Sedangkan program paket yang digunakan, beberapa bagian pun sudah menggunakan Microsoft Office 2007 dalam mengerjakan dan mengolah data

\section{Perangkat Akal (Brainware)}

Pemberdayaan SDM dalam sistem komputerisasi yang selama ini dimiliki oleh SMPN 3 Mallusetasi hanya meliputi beberapa orang operator yaitu; guru sebanyak 8 orang, pegawai 4 orang, dan siswa belum ada satupun yang berada dalam kategori mahir.

Pada bagian TU ada 1 orang operator yang belum mahir dan mempunyai tugas menginput data, mengolah, dan mencetak laporan bulanan dan administrasi persuratan. Operator ini dalam melaksanakan tugasnya pada mulanya dibantu oleh seorang guru. Sehingga untuk mempermahir, maka penulis mendampinginya dan sampai sekarang sudah dapat melakukannya sendiri tanpa didampingi. Mulai dari menginput, mengolah sampai mencetak surat-surat maupun laporan-laporan baik dalam MS Word maupun MS Excel.

Pada bagian pembukuan dan akuntansi terdapat 1 orang operator yakni bendahara sendiri yang baru belajar. Pembukuan dan akuntansi memiliki program tersendiri yaitu, program akuntansi maupun bendahara. Dalam melakukan penginputan, pengolahan data dan pencetakan laporan kas sekolah masih dibantu oleh guru.

Komputer pada ruang Kepala Sekolah digunakan untuk memproses data-data administrasi kepala sekolah. Operatornya adalah kepala sekolah sendiri yang dibantu oleh seorang staf tata usaha.

Komputer pada ruang laboratorium dikelola khusus oleh guru TIK sendiri. Dimana dalam melaksanakan praktek digunakan jadwal tersendiri. Untuk masing-masing komputer digunakan oleh 2 orang siswa secara bergiliran.

\section{Perencanaan Sistem Jaringan}

\section{Hardware}

Perangkat keras yang dibutuhkan untuk membangun sebuah jaringan komputer yaitu : Komputer, Card Network, Hub, dan segala sesuatu yang berhubungan dengan koneksi jaringan seperti: Bridges, Router dan lainnya yang dibutuhkan untuk proses transformasi data didalam jaringan

a. PC

Dalam perancangan jaringan komputer ini kami menggunakan PC sebagaimana pada table spesifikasi tersebut pada bagian sebelumnya. Kami menggunakan 10 komputer, 7 komputer untuk Laboratorium, 3 PC untuk kantor. Kami akan menghubungkan komputer tersebut dalam satu jaringan komputer dan ditambah dengan access point untuk jaringan nirkabel.

b. Network Interface Cards (NIC) dan Ethernet Card/Kartu Jaringan

Kartu Jaringan merupakan perangkat yang menyediakan media untuk menghubungkan antar komputer. Kartu jaringan yang kita gunakan adalah kartu jaringan yang onboard (tertanam dalam mainboard).

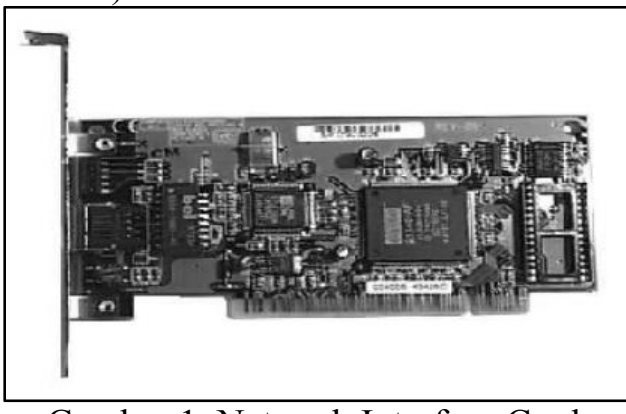

Gambar 1. Network Interface Card

\section{c. $H U B$}

Sebuah Konsentrator/Hub adalah sebuah perangkat yang menyatukan kabelkabel network dari tiap-tiap workstation, server atau perangkat lain. Hub yang akan kami gunakan dalam perancangan jaringan 
adalah Hub TP-Link 16 Port sebanyak 2 (dua) buah.

Hub yang pertama kami gunakan pada laboratorium komputer, Hub ini akan menghubungkan 8 (delapan) client dan satu buah server, dan menghubungkan kantor dengan laboratorium. Hub yang kedua digunakan pada kantor, Hub ini menghubungkan 3 (tiga) komputer yang berada di kantor, menghubungkan antara laboratorium. Dan yang terpenting Hub ini menghubungkan modem dengan access point yang berada di ruang guru.

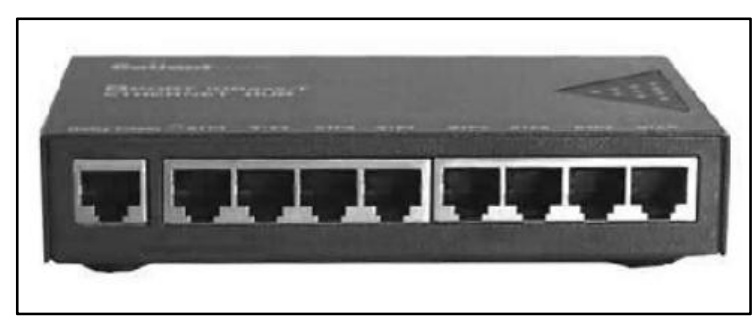

Gambar 2. HUB

\section{d. Mikrotik Routerboard 750}

Untuk merutekan paket data dalam perancangan jaringan ini kami menggunakan Mikrotik Routerboard 750. Dengan pertimbangan Mikrotik RB 750 mempunyai keunggulan dari segi ekonomis dan kemampuan yang dimiliki oleh Mikrotik RB 750 ini juga tidak terlalu buruk. Kami menggunakan Mikrotik RB 750 sebagi router untuk mengirimkan paket data dari modem ADSL menuju Accsess point yang berada di ruang guru dan Hub utama Laboratorium.

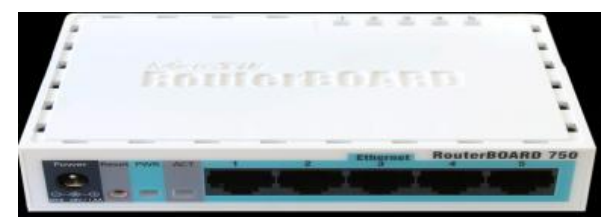

Gambar 4. Mikrotik Routerboard 750

\section{e. Kabel Jaringan}

Dalam sebuah jaringan kita tak pernah lepas dari kabel yang digunakan. Dalam perancangan jaringan ini kami menggunakan kabel UTP, kami memilih kabel UPT belden karena lebih tahan terhadap cuaca panas karena lapisan pembungkusnya lebih tebal dan lebih praktis meski harganya sedikit lebih mahal.

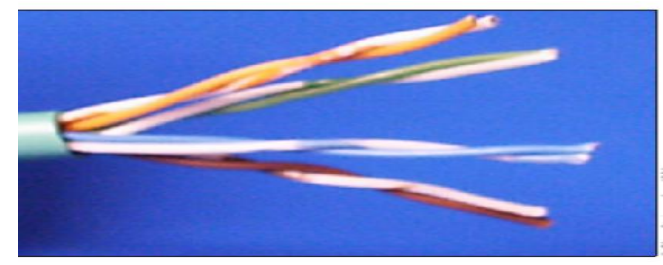

Gambar 4. Kabel UTP Belden

\section{b. Modem}

Modem dalam jaringan sangat penting peranannya, kami memilih modem TP-Link TD 108, untuk kelas modem TP-Link ini merupakan modem standar. Modem ini juga yang disaranka oleh telkom sebagai provider internet.

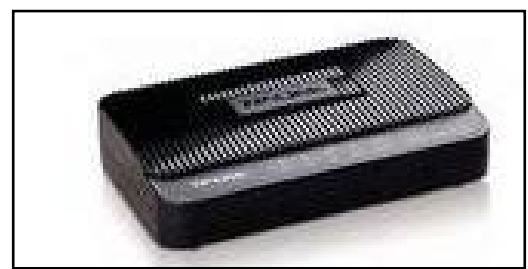

Gambar 5. Modem ADSL TP-LINK

\section{c. Access Point}

Jaringan nirkabel, hal yang terpenting adalah Access Point. Kami menggunakan access point belkin untuk jaringan nirkabel yang jangkauannya $100 \mathrm{~m}$ dan access point ini tak membutuhkan configurasi untuk menfungsikannya.

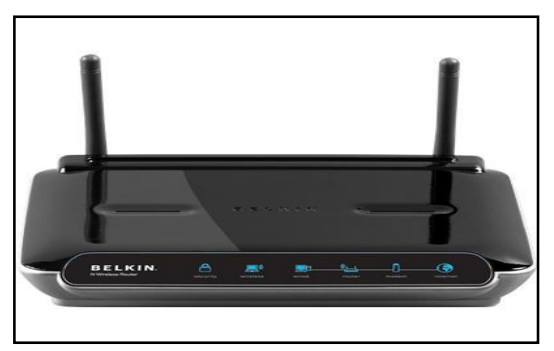

Gambar 6. access point belkin

\section{Software}

Sistem operasi merupakan suatu komponen penting dalam membangun suatu jaringan, karena sistem operasi jaringan berfungsi sebagai pembentuk pola operasi jaringan. Dalam jaringan ini kami memilih Windows XP sebagai system operasi karena kurikulum yang diajarkan di sekolah menggunakan system operasi Windows dan kebanyakan user lebih mengerti menggunakan windows dibanding operasi system yang lain.

\section{Topologi Jaringan}

Jaringan LAN yang menggunakan wireless ada beberapa langkah yang harus 
dilakukan sehingga jaringan yang dibuat dapat bekerja dengan baik dan data-data yang didapat sesuai dengan yang diharapkan. Berikut adalah rancangan jaringan yang akan dibuat, yaitu:

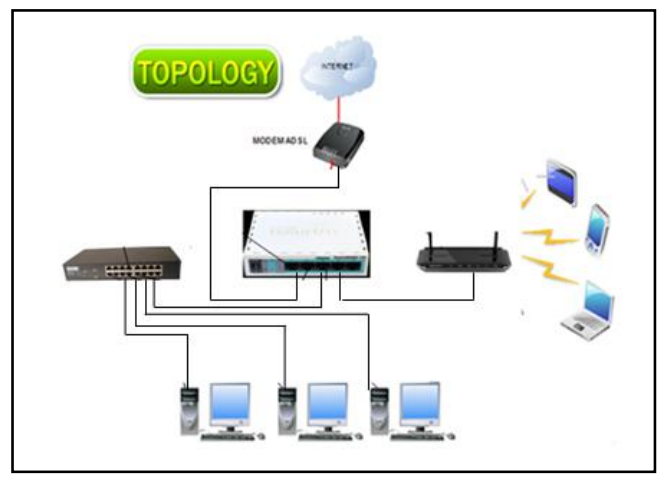

Gambar 7. Topologi Jaringan

\section{Configurasi IP Address}

Konfigurasi setting IP Addres komputer. Cara Configurasi IP Address, yaitu;

- Click Start | Setting | Control Panel sampai keluar kotak dialog Control Panel.

- Double-Click Icon Network Connection sampai keluar kotak dialog Network Connection.

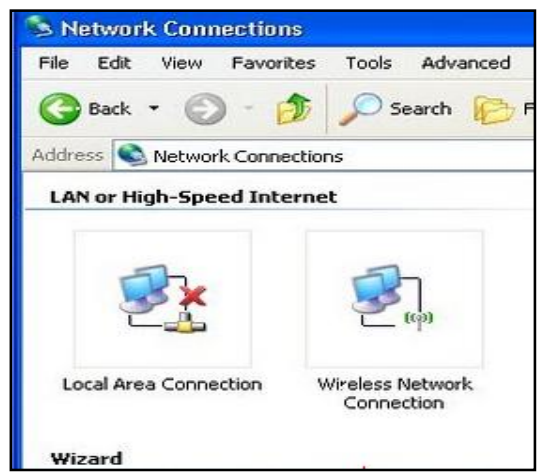

Gambar 8 Dialog Network Connection

- Double-click Icon Local Area Connection sampai keluar kotak dialog Local Connection Area Status.

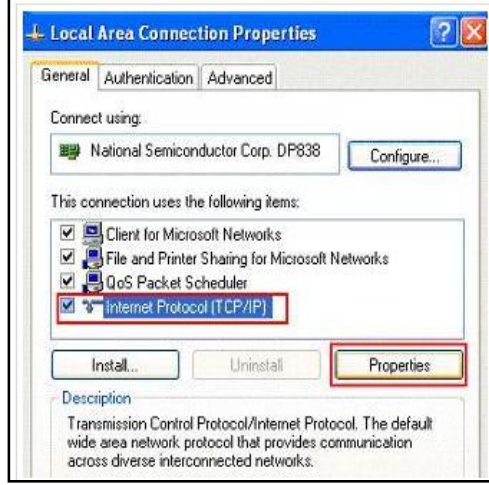

Gambar 9. Dialog LAN Area Connection
Double-Click Internet Protocol (TCP/IP) yang ada di dalam kotak dialog Local Area ConnectionProperties sampai keluar kotak dialog baru : Internet Protocol (TCP/IP) Protocol.

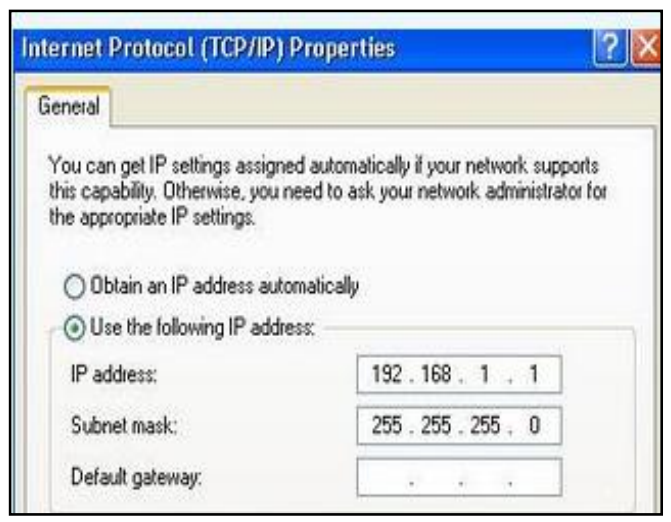

Gambar 10. Dialog TCP/IP

Klik use the following IP Address, Masukkan data-data IP Address. IP Address computer 1; 192.168.1.1; komputer 2: 192.168.1.2 dst, dengan subnet mask 255.255.255.0, sedangkan untuk gateway dikosongkan saja, karena jaringan LAN tidak terhubung ke jaringan LAN lain/internet.

- Setelah data-data setting TCP/IP ini dimasukkan, click OK untuk menutup kotak dialog Internet Connection (TCP/IP) Properties.

- Click OK untuk menutup kotak dialog "Local Area Connection Properties"

Selanjutnya untuk settingan Ip Address client langkanhya sama yang membedakan hanya IP Addressnya, kalau pada server kita mengisinya dengan 192.168.1.1, pada client 1 IP Addressnya kita isikan dengan 192.168.1.2. begitupun dengan client 2-8 berurutan tidak oleh ada IP Address yang sama

\section{Rancangan Jaringan SMPN 3 Mallusetasi}

Setelah kami konfigurasi dan merancang jaringan komputer tiap ruangan mulai dari laboratorium, kantor, dan ruang guru. Selanjutnya kami menghubungkan ketiga ruangan tersebut untuk menghasilkan satu jaringan komputer yang saling terhubung satu sama lain. 


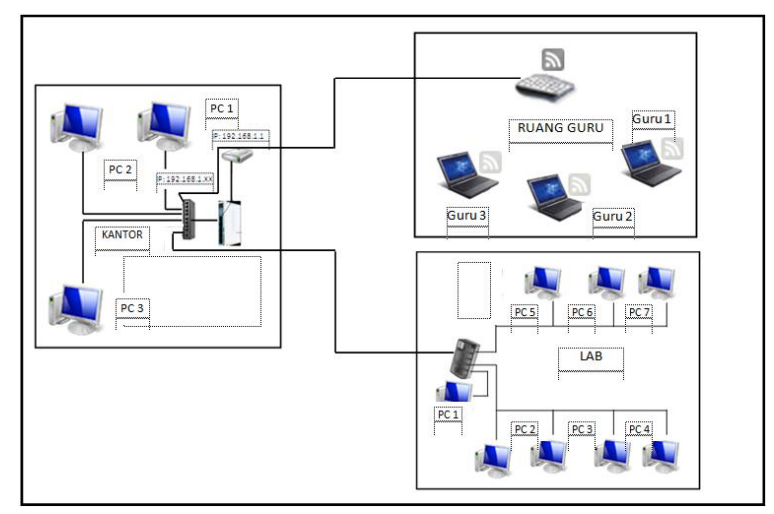

Gambar 11. Rancangan Jaringan Komputer SMPN 3 Mallusetasi

Keterangan:

1. Kantor

- $\quad$ PC1 $\rightarrow$ IP : 192.168.1.2

- $\quad \mathrm{PC} 2 \rightarrow \mathrm{IP}: 192.168 .1 .3$

- $\quad \mathrm{PC} 3 \rightarrow \mathrm{IP}: 192.168 .1 .4$

2. Laboratorium

- $\quad \mathrm{PC} 4 \rightarrow \mathrm{IP}: 192.168 .1 .5$

- $\quad \mathrm{PC} 5 \rightarrow \mathrm{IP}: 192.168 .1 .100$

- $\quad$ PC6 $\rightarrow$ IP : 192.168.1.101

- $\quad \mathrm{PC} 7 \rightarrow$ IP : 192.168.1.102

- $\quad \mathrm{PC} 8 \rightarrow \mathrm{IP}: 192.168 .1 .103$

- $\quad \mathrm{PC} 9 \rightarrow \mathrm{IP}: 192.168 .1 .104$

- $\quad \mathrm{PC} 10 \rightarrow \mathrm{IP}: 192.168 .1 .105$

\section{Pengujian Konfigurasi Modem TP Link}

Metode pengujian yang digunakan adalah metode blackbox testing, sistem dipandang sebagai kotak hitam yang tidak diketahui isinya. Pengujian dilakukan dengan memberikan input kepada sistem dan mengamati apakah output yang dihasilkan sesuai dengan harapan. Metode pengujian ini sangat tepat digunakan untuk mengetahui apakah sistem bekerja dengan baik, karena apabila sistem memberikan output yang tidak sesuai, berarti telah terjadi kesalahan dalam sistem.

- Langkah pertama yang perlu kita lakukan adalah koneksikan modem dengan jaringan telepon dan komputer, setelah semua terhubung buka browser, masukkan alamat IP modem Anda dalam Address bar browser. Defaultnya adalah 192.168.1.1, kemudian tekan Enter

- Ketika muncul jendela Authentification Required, masukkan username dan password;
Gambar 12. Tampilan memulai konfigurasi modem

Default dari vendor adalah: User Name : admin

Password : admin.

- Pada halaman utama pilih Quick Start > Run Wizard.

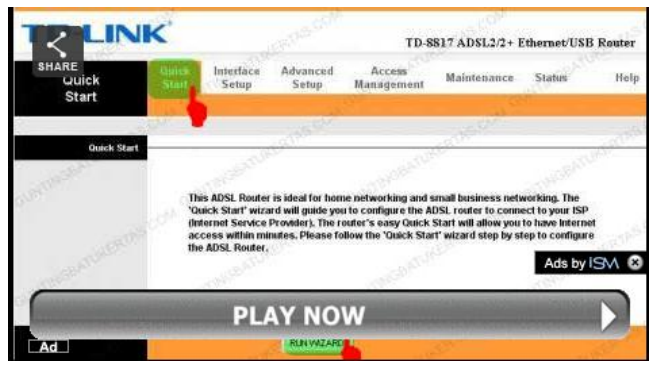

Gambar 13. Tampilan Run Wizard

- Pada tampilan berikut, klik Next.

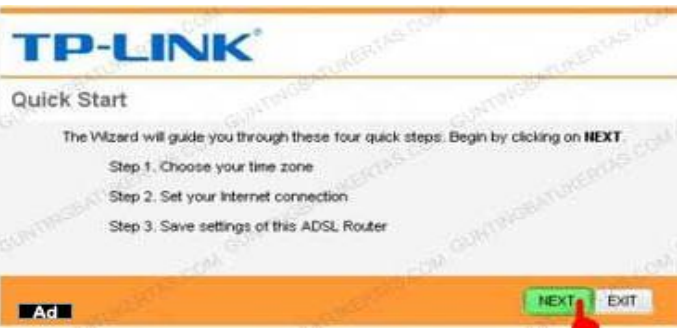

Gambar 14. Tampilan Quick Start

- Pilih Zona waktu menjadi (GMT+07:00) Bangkok, Jakarta, Hanoi. Kemudian klik Next.

\section{TP-LINK}

\section{Quick Start - Time Zone}

Select the approprizte the zone for you locoton and cidi HEXT to contrue. (OAT*0700) Barglad, Juarta, Hind

ad BACK IEXT EXT

Gambar 15. Tampilan pemilihan zona waktu

- Pilih tipe koneksi PPPoE/PPPoA. Kemudian klik Next.

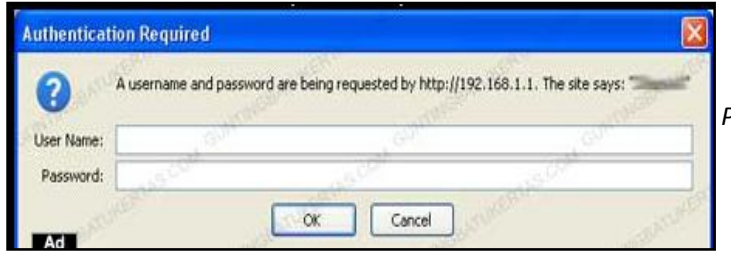

\begin{tabular}{|c|c|}
\hline \multirow{5}{*}{ Perancangan } & TIP-LINRK \\
\hline & $\begin{array}{l}\text { Quick Start - ISP Connection Type } \\
\text { select the reernet connection type to compect to your sp chack } n\end{array}$ \\
\hline & 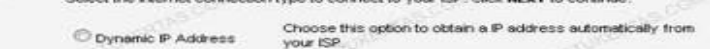 \\
\hline & 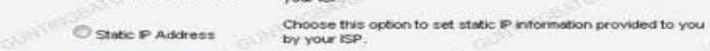 \\
\hline & 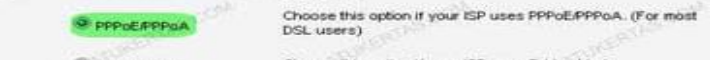 \\
\hline
\end{tabular}


Gambar 16. Tampilan koneksi PPPoE/PPPoA

- Pada konfigurasi berikut, masukkan:

\# Username : nomerspeedy@telkom.net

\# Password : password

\# VPI: 0

\# VCI : 35

\# Connection Type : PPPoE LLc.

\# selanjutnya klik Next

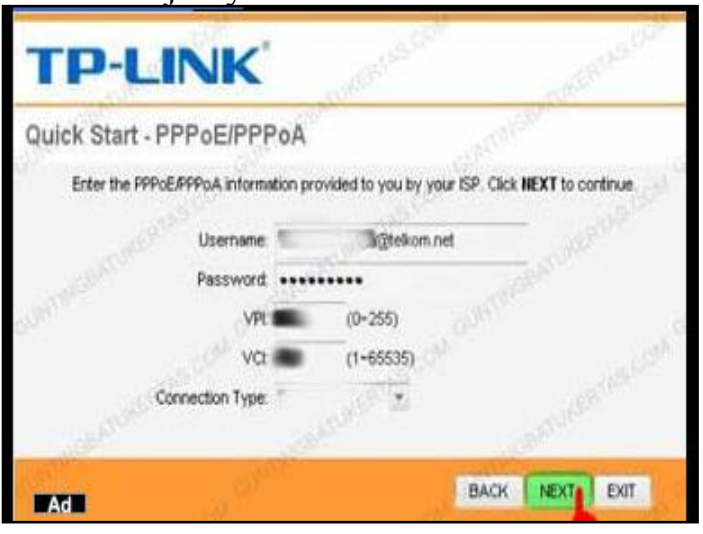

- Jika Anda sudah yakin, Klik Next. Jika belum, Anda bisa klik Back dan melakukan beberapa penyesuaian.

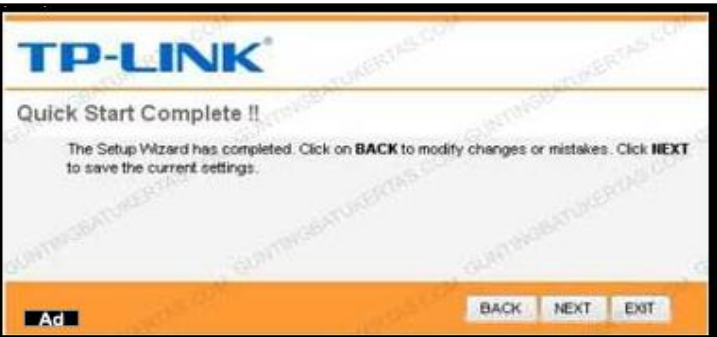

- Klik Close, dan Restart Modem Anda.

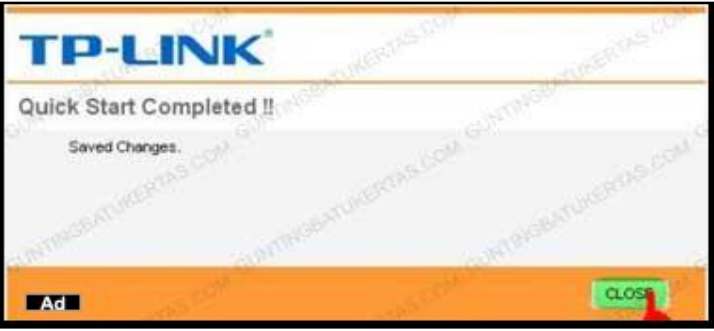

Gambar 17. Tampilan untuk memasukkan password

Tabel 5.1 Pengujian Modem

\begin{tabular}{|c|c|l|}
\hline Test Factor & Hasil & \multicolumn{1}{|c|}{ Keterangan } \\
\hline Pengujian Configurasi Modem & $\sqrt{ }$ & $\begin{array}{l}\text { Berhasil, karena muncul pesan quick } \\
\text { start complete dan meminta menyimpan } \\
\text { perubahan. }\end{array}$ \\
\hline
\end{tabular}

\section{Konfigurasi Hotspot Mikrotik}

Setting Hotspot pada Mikrotik Router OS sangat mudah dikonfigurasi. Sistem autentikasi hotspot biasa digunakan ketika kita akan menyediakan akses internet pada areal publik, seperti : Hotel, café, Kampus, airport, taman, mall dll. Teknologi akses internet ini biasanya menggunakan jaringan wireless atau wired. Biasanya menyediakan akses internet gratis dengan menggunakan hotspot atau bisa juga menggunakan Voucher untuk autentikasinya. Ketika membuka halaman web maka router akan mengecek apakah user sudah di autentikasi atau belum. Jika belum melakukan autentikasi, maka user akan di arahkan pada hotspot login page yang mengharuskan mengisi username dan password. Jika informasi login yang dimasukkan sudah benar, maka router akan memasukkan user tersebut kedalam sistem hotspot dan client sudah bisa mengakses halaman web.

Selain itu akan muncul popup windows berisi status ip address, byte rate dan time live. Penggunaan akses internet hotspot dapat dihitung berdasarkan waktu (time-based) dan data yang di download/upload (volume-based). Selain itu dapat juga dilakukan melimit bandwidth berdasarkan data rate, total data upload/download atau bisa juga di limit berdasarkan lama pemakaian.

Cara mudah setting hotspot pada mikrotik adalah ada 2 (dua) pilihan selain menggunakan teks mode kita juga bisa 
menggunakan setting wizard dengan menggunakan Winbox Router OS, Langkahlangkat berikut merupakan konfigurasi dasar hotspot mikrotik sebagai Gateway Server. Pertama install Mikrotik Router OS pada PC atau pasang DOM atau kalau menggunakan Router Board langsung aja Login = 'admin' sedangkan untuk pasword dikosongkan saja untuk defaultnya.

\section{Masuk ke IP $==>$ Hotspot $==>$ Setup}

Kemudian tentukan IP lokal hospot yang akan digunakan, misal 192.168.10.1 dan Tentukan IP DHCP ke clientnya yang akan digunakan, dalam contoh ini adalah 192.168.10.2-192.168.10.255

Untuk SMTP Server sebaiknya dikosongkan saja, Kemudian DNS servernya diisikan sesuai dengan Provider, dalam contoh ini adalah DNS1 $=202.47 .78 .1$ DNS2 $=202.47 .78 .9$

DNS lokal hotspot anda NEXT saja kemudian pada Hotspot user anda dalam contoh berikut diisi admin password admin 123

Hotspot Server Profile digunakan untuk mensetting server yang akan sering digunakan untuk semua user seperti metode autentikasi dan Limitasi data rate. Ada 6 jenis autentikasi Hotspot mikrotik yang berbeda dalam profile setting, jenis autentikas tersebut adalah : HTTP PAP, HTTP CHAP, HTTPS, HTTP cookie, MAC address, Trial. Metode autentikasi yang akan digunakan, biasanya cukup menggunakan metode HTTP CHAP.

Data rate limitation digunakan sebagai default setting untuk user yang belum di setting bandwidth limit pemakaiannya. Dimana RX adalah Client upload dan TX adalah Client download. Misal setting default data rate di 64k/128k (upload/download).

Hotspot user profile digunakan untuk menyimpan data user yang akan dibuatkan rule profilenya. Dimana didalamnya bisa dilakukan setting firewall filter chain untuk traffic yang keluar/masuk, juga bisa untuk mensetting limitasi data rate dan selain itu dapat juga dilakukan paket marking untuk setiap user yang masuk kedalam profile tersebut secara otomatis.

Hotspot user yaitu nama-nama user yang akan diautentikasi pada sistem hotspot. Beberapa hal yang dapat dilakukan dalam konfigurasi hotspot user yaitu: username dan password, Membatasi user berdasarkan waktu dan paket data yang akan digunakan, hanya ip address tertentu dari ip address dhcp yang ditawarkan atau hanya mengizinkan user untuk koneksi ke sistem hotspot dari MAC Address tertentu saja.

IP Bindings digunakan untuk mengizinkan ip tertentu untuk membypass autentikasi hotpot, ini sangat berguna sekali ketika kita ingin menjalankan layanan server, atau IP telephon di bawah system hotspot. Misal, PC atau Notebook anda untuk dapat membypass hotspot system, dengan demikian kita dapat melakukan browsing tanpa autentikasi

\section{KESIMPULAN \& SARAN}

Jaringan komputer adalah sekelompok komputer yang saling berhubungan satu sama lain dengan memanfaatkan media komunikasi dan suatu protokol komunikasi, sehingga antar komputer dapat saling berbagi dan bertukar informasi. Perancangan jaringan pada SMPN 3 Mallusetasi yang menggabungkan antara tiga gedung yaitu, kantor, laboratorium komputer, dan ruang guru, ditambah lagi dengan satu titik access point sebagai akses wireless. Lebih memudahkan dalam mendapatkan informasi serta memudahkan dalam proses belajar mengajar.

Berdasarkan kesimpulan di atas, maka penulis menyarankan kepada beberapa pihak yang terlibat, yaitu:

1. Kepada guru, agar kiranya dapat memanfaatkan koneksi jaringan ini untuk hal-hal yang bermanfaat baik sebagai sarana pelatihan maupun sarana mengakses pengetahuan yang terkait dengan proses pembelajaran di kelas.

2. Kepada siswa, di sarankan untuk memanfaatkan sarana jaringan ini sebagai salah satu sarana belajar maupun sebagai sumber informasi pengetahuan yang terkait dengan tugas-tugas di sekolah.

3. Kepada kepala sekolah, kiranya dapat melakukan perawatan dan pemeliharaan secara periodic melalui sumber anggaran yang sesuai.

\section{DAFTAR PUSTAKA}

Ahmad Yani. 2008. Panduan Membangun Jaringan Komputer. Bandung

Berry Krcheval dan Dwi Prabautini. 2009. DHCP Panduan untuk Konfigurasi Jaringan TCP/IP yang Dinamis. Yogyakarta

Fathan Syah, Ir. 2012. Basis Data, Informatika:Bandung 
Firrar Utdirartarmo. 2014. Cara Mudah Mengelolah PC dalam Jaringan. Yogyakarta

Hakim Lukmanul, 2010, Jalan pintas menjadi Master PHP, Yogyakarta

Heywood Drew dan Daniel M.W. 1996. Konsep dan Penerapan. Microsoft $T C P / I P$. Yogyakarta

Janner Simarmata, 2007. Perancangan Basis Data. Andi Offset, Yogyakarta.

Jogiyanto, H.M., 2015, Pengenalan Komputer, Andi Offset, Yogyakarta.

Melwin. Sya Frizal. 2015. Pengantar Jaringan Komputer. Yogyakarta

Sutarman, 2013. Membangun Aplikasi Web dengan PHP dan MySQL, Graha Ilmu, Yogyakarta , 2017. Pengenalan Mikrotik. http://mikrotik.co.id) diakses pada tanggal 21 Mei 2011

, 2017 Pengenalan Jaringan dan Konfigurasinya.

http://www.smarteknologi. info/ , 2017.http://ilmukomputer.org/ , 2017.http://blog.beoco.or.id/?p=165

2017.http://suryana.or.id/2006/06/01/k onfigurasi-wireless-access-point/ ,2011

http://www.kotainternet.com/konfigura si-hotspot-mikrotik.html

Sopandi Dede.2008.Instalasi Dan Konfigurasi Jaringan Komputer.Bandung: Informatika

Tri Kuntoro Priyambodo, dan Dodi Heriadi. 2005. Jaringan WIFI, Teori dan Implementasi. Yogyakarta

Wahana Komputer. 2005. Menjadi Administrator Jaringan Komputer. Semarang 